\title{
Numeracy and Risk Literacy: What Have We Learned so Far?
}

\author{
Rocio Garcia-Retamero¹, Agata Sobkow ${ }^{2}$, Dafina Petrova ${ }^{3}$, Dunia Garrido ${ }^{1}$ and Jakub Traczyk ${ }^{2}$ \\ 1 Universidad de Granada (Spain) \\ 2 SWPS University of Social Sciences and Humanities (Poland) \\ ${ }^{3}$ Instituto de Investigación Biosanitaria ibs. Granada (Spain)
}

\begin{abstract}
Numerical skills are essential to make informed decisions in our daily life. Unfortunately, many people lack basic numeracy, which limits their ability to accurately interpret risks (i.e., risk literacy). In this paper, we provide an overview of research investigating the role of numeracy in two prominent domains, where most research was concentrated, health and finance. We summarize what has been learned so far in these domains and suggest promising venues for future research. We conclude that it is important to conduct interventions to improve numeracy in less numerate individuals and to help them make informed decisions and achieve better life outcomes.
\end{abstract}

Received 4 June 2018; Revised 4 February 2019; Accepted 6 February 2019

Keywords: finance, health, informed decision making, numeracy, risk literacy.

Imagine that your lifetime risk of developing bowel cancer is about 1 in 23 . Now imagine that regularly undergoing screening can reduce this risk by $40 \%$. However, the screening might occasionally result in bowel perforation, which is a dangerous condition and the risk of this happening is $2 \%$. In addition, you need to pay for it and it would increase your annual health spending with about 80 Euros. Would you get screened regularly? Can you afford it? Is it worth it?

This example illustrates one of the many decisions that people regularly face in which numerical information is abundant and outcomes are uncertain. It also illustrates that in order to make informed decisions, it is now more important than ever to have adequate numerical skills or numeracy-i.e., the ability to understand and use numbers, perform arithmetic operations and compare numerical magnitudes (Ancker \& Kaufman, 2007; Cokely, Galesic,

The second affiliation of Rocio Garcia-Retamero is Harding Center for Risk Literacy, Max Planck Institute for Human Development, Berlin (Germany). The second and third affiliations of Dafina Petrova are Escuela Andaluza de Salud Pública (EASP), Granada (Spain); and CIBER de Epidemiología y Salud Pública (CIBERESP), Madrid (Spain). Correspondence concerning this article should be addressed to Rocio Garcia-Retamero. Universidad de Granada. Departamento de Psicología Experimental. Campus de Cartuja S/N. 18071 Granada (Spain).

E-mail: rretamer@ugr.es

This research was supported by a grant from the Ministerio de Economía y Competitividad (Spain) (PSI2011-22954 and PSI201451842-R), the Max Planck Society (Germany), the National Science Centre (Poland) (2015/17/D/HS6/00703), the SWPS University of Social Sciences and Humanities (Poland) (BST/Wroc/2016/B/7), and Dafina Petrova is supported by a Juan de la Cierva Fellowship (FJCI-2016-28279) from the Spanish Ministry of Economy, Industry, and Competitiveness.
Schulz, Ghazal, \& García-Retamero, 2012; Fagerlin, Ubel, Smith, \& Zikmund-Fisher, 2007; Peters, 2012). In addition, being able to compute proportions, percentages, or probabilities - often referred to as statistical numeracy (Cokely, Ghazal, \& García-Retamero, 2014)— is especially important when decisions involve risk and uncertainty, as is often the case in the domains of health and finance; and it is fundamental for risk literacy -one's practical ability to evaluate and understand risk in the service of skilled and informed decision making (Cokely et al., 2018).

In the past twenty years, since the publication of the first brief statistical numeracy test by Schwartz and colleagues (Schwartz, Woloshin, Black, \& Welch, 1997), an increasing amount of research has addressed the importance of numeracy across a variety of contexts (see Reyna, Nelson, Han, \& Dieckman, 2009 for a review). Overall, this research has shown that low numeracy is pervasive and generally associated with disadvantageous outcomes. Here we give a brief, illustrative overview of research investigating the role of numeracy in two prominent domains, where most research was concentrated, health and finance. Rather than being exhaustive, our goal is to summarize what has been learned so far and suggest promising venues for future research. The studies reviewed here concern mostly, though not exclusively, statistical numeracy. In the first section, we illustrate the prevalence of low

How to cite this article:

Garcia-Retamero, R., Sobkow, A., Petrova, D., Garrido, D., \& Traczyk, J. (2019). Numeracy and risk literacy: What have we learned so far? The Spanish Journal of Psychology, 22. e10. Doi:10.1017/sjp.2019.16 
numeracy, and its implications for decisions about health and health outcomes. In the second section, focusing on studies from the financial domain, we illustrate the underlying mechanisms that drive the effects of numeracy on financial decisions and outcomes. Finally, we discuss the urgent need for interventions that can demonstrate how we can use numeracy to help people make informed decisions and achieve better life outcomes. Important aspects that are not broadly covered in the current review but might be of interest to readers are relevant theoretical models (e.g., the skilled decision theory, Cokely et al., 2018; and the fuzzy trace theory, Broniatowski \& Reyna, 2017), recommendations regarding the measurement of numeracy and the available instruments (see Cokely et al., 2014), and the components of numeracy and their distinct roles in the decision making process (see Peters \& Bjalkebring, 2015).

\section{Influence of numeracy on health}

Numerical skills are essential for navigating in the modern health care environment. To illustrate, physicians often need to interpret and communicate information about the benefits and risks of different medical treatments, screenings, and lifestyle choices (Anderson \& Schulkin, 2014), and patients need to understand and use this information to consent on their own behalf to medical treatment and to adhere to medical advice (Zikmund-Fisher, Mayman, \& Fagerlin, 2014).

Most of the research investigating numerical skills in patients used an 11-question test developed by Schwartz et al. (1997) and Lipkus, Samsa, and Rimer (2001). The test specifically assesses practical knowledge of basic probabilistic concepts and mathematical operations, including comparing risk magnitudes, converting percentages to proportions out of one, converting proportions to percentages, converting probabilities to proportions out of one, and computing probabilities. Examples of items from the test are "Which of the following numbers represents the biggest risk of getting a disease? 1 in 10, 1 in 100, or 1 in 1,000 ?" and "If the chance of getting a disease is 20 out of 100 , this would be the same as having a __\% chance of getting the disease." Unfortunately research using this test showed that many patients do not have the skills necessary for accurate, unaided evaluation of risks (Cokely, Ghazak, Galesic, GarcíaRetamero, \& Schulz, 2012; García-Retamero \& Galesic, 2013). For instance, Rodríguez et al. (2013) showed that more than $40 \%$ of the patients in the US incorrectly answered most of these items developed by Schwartz et al. (1997) and Lipkus et al. (2001) described above (see also Gaissmaier et al., 2018). This research converges with other studies conducted on general community samples (Galesic \& García-Retamero, 2010; Kutner, Greenburg, Jin, \& Paulsen, 2006; Lipkus et al., 2001), indicating the common struggles people often have with basic numerical concepts: Many people do not possess basic, practical mathematical skills that are often essential for independent risk evaluation and general skilled decision making in the context of health.

Previous research also showed that numeracy is one of the best predictors of important outcomes in health and medical decision making. García-Retamero and Cokely (2017) conducted a systematic review and an analysis of the available literature on this topic. The authors concluded that numeracy is robustly related to (a) the accuracy of perceptions of health-related benefits and risks in patients; (b) the quality of medical decision making and shared decision making between doctors and patients, and (c) health outcomes in patients.

Patients with low numeracy often have less accurate perceptions of the benefits and risks of medical treatments and interventions. Compared with patients with high numeracy, less numerate patients overestimate their personal risk of suffering several diseases (Davids, Schapira, McAuliffe, \& Nattinger, 2004; Gurmankin, Baron, \& Armstrong, 2004), and they overestimate the efficacy of uncertain treatments (Weinfurt et al., 2003). Patients with low numeracy also have more difficulty interpreting the risks of side effects (Gardner, McMillan, Raynor, Woolf, \& Knapp, 2011) and understanding the information necessary to follow dietary recommendations (Rothman et al., 2006). Patients with low numeracy also make less accurate diagnostic inferences based on numerical information about screening (GarcíaRetamero, Cokely, \& Hoffrage, 2015; García-Retamero \& Hoffrage, 2013; Gigerenzer, Gaissmaier, Kurz-Milcke, Schwartz, \& Woloshin, 2007; Petrova, García-Retamero, Catena, \& van der Pligt, 2016) and are less able to use this diagnostic information to adjust their risk estimates (Schwartz et al., 1997). Research on the underlying mechanisms shows that people with low numeracy have difficulties reasoning about the underlying relationships in the data (Johnson \& Tubau, 2017) and do no benefit from interventions that clarify the causal structure of the data (McNair \& Feeney, 2015). Finally, less numerate patients are more easily biased by the way health-related numerical information is framed (García-Retamero \& Galesic, 2009, 2010, 2011; Peters \& Levin, 2008; Peters et al., 2006). This inaccuracy of perceptions of health-related benefits and risks may cascade, thereby influencing patients' efforts to promote health and prevent disease, and efforts to comply with diagnosis and treatment directives (Paasche-Orlow \& Wolf, 2007; von Wagner, Steptoe, Wolf, \& Wardle, 2009).

Numeracy also affects the quality of medical decision making, which may influence shared decision making. 
Compared with patients with high numeracy, less numerate patients often make less accurate decisions based on numerical information about screening and the risk of suffering a disease (García-Retamero \& Cokely, 2014; Petrova et al., 2016). For instance, many patients with low numeracy would go through screening when the test does not show benefits. Physicians' levels of numeracy can also influence the quality of patients' decisions as less numerate physicians often offer lower quality risk communication to their patients (e.g., they are less likely to mention risks of important harms of screenings; Petrova, Kostopoulou, Delaney, Cokely, \& GarcíaRetamero, 2017).

Less numerate patients also tend to favor a paternalistic model of medical decision making, in which doctors are dominant and autonomous and make decisions on their patients' behalf (García-Retamero, Wicki, Cokely, \& Hanson, 2014), whereas patients prefer not to participate and instead delegate decision making (Galesic \& García-Retamero, 2011). This finding is troubling given that the paternalistic model of medical decision making has well-documented ethical and practical limitations (e.g., it prevents or limits patients' ability for self-determination) (Kaplan \& Frosch, 2005). Accordingly, patients with low numeracy are more likely to report negative interactions with their doctors (Manganello \& Clayman, 2011; Roter, 2005), which influence their subsequent information search and their ability to engage in decision making (McCaffery, Smith, \& Wolf, 2010). For instance, less numerate patients often avoid asking doctors questions about their symptoms and medical treatments (PaascheOrlow \& Wolf, 2007), they tend to spend less time gathering information about their disease during medical sessions (Portnoy, Roter, \& Erby, 2010), and they rarely use personal health records on the Internet (Sharit et al., 2014).

Results in accuracy of perceptions and quality of medical decision making often translate into important health outcomes, including disease management, quality of life, risk of hospitalization and prevalence of comorbidity. For instance, low levels of numeracy predict patients' difficulty following a complex dosing regimen (Estrada, Martin-Hryniewicz, Collins, Byrd, \& Peek, 2004; Waldrop-Valverde, Jones, Gould, Kumar, \& Ownby, 2010), their total body mass index (Huizinga, Beech, Cavanaugh, Elasy, \& Rothman, 2008), and their activity limitations as well as struggles with emotional functioning (Apter et al., 2009). Low levels of numeracy also predict more frequent utilization of emergency department services (Apter et al., 2006; Ginde, Clark, Goldstein, \& Camargo, 2008) and longer delays when seeking medical attention, which can dramatically increase patients' risk for death and major disability (Petrova et al., 2017).
Compared with patients with more developed numerical skills, less numerate patients are also at greater risk for comorbid conditions, including myocardial infarction, chronic obstructive pulmonary disease, peptic ulcer disease, liver disease, diabetes, and HIV / AIDS (García-Retamero, Andrade, Sharit, \& Ruiz, 2015; Petrova et al., 2017). On average, the relative risk that patients with low numeracy suffer one of these diseases is roughly $40 \%$ greater than that of patients with high numeracy. Patients with low numeracy also take $20 \%$ more prescribed medication than those with higher numerical skills (García-Retamero et al., 2015). These findings hold statistically after controlling for the effect of key demographics (e.g., age, education, ethnicity, and household income) and body mass index, suggesting that numeracy has a unique relationship with health outcomes above and beyond the effect of these factors.

In summary, there is a large and consistent body of research in health and medical decision making showing that many people have problems understanding health-relevant numerical expressions of probability about health. This research indicates that many people are functionally innumerate, making them vulnerable to health problems regardless of other protective factors. In contrast, people who have well developed numerical skills tend to have more accurate perceptions of health-related benefits and risks, and often make better decisions that translate into important health benefits (e.g., lower prevalence of comorbidity).

\section{Influence of numeracy on financial decision making}

A great body of evidence accumulated in the last decade has also shown that statistical numeracy is one of the strongest unique predictors of superior decision making in the financial domain (e.g., Estrada-Mejía, de Vries, \& Zeelenberg, 2016; Ghazal, Cokely, \& GarcíaRetamero, 2014; Pachur \& Galesic, 2013; Petrova, van der Pligt, \& García-Retamero, 2014; Traczyk, Lenda, et al., 2018; Traczyk, Sobkow, et al., 2018; Traczyk \& Fulawka, 2016). Numeracy helps make better decisions in paradigmatic risk tasks (e.g., risky prospect evaluation) tested in laboratory settings; numeracy is also crucial to real-life financial decision making measured outside the lab by objective economic variables. In this section, we focus on studies that demonstrated the role of numeracy in basic financial paradigmatic risk tasks, discussing possible moderators and cognitive mechanisms that are likely to explain better performance of more numerate people in financial tasks. Next, we present some recent findings showing that effects of numeracy on financial decisions are not limited to simple monetary lotteries, but can be also observed "in the wild" explaining economic and societal outcomes. 
The role of numeracy in paradigmatic risk tasks

In economic theory, optimal behavior under risk and uncertainty is defined by variants of expected value or expected utility models (Starmer, 2000). For instance, expected utility theory (von Neumann \& Morgenstern, 1944) posits that a rational decision maker selects alternatives that maximize expected utility - "a measure of extent of goal achievement" (Baron, 2008, p. 233). In the financial domain, this goal is often realized by gaining more money and can be accomplished by following the rule of expected value/utility maximization. That is, if a person considers whether to choose lower but sure 5 EUR payoff or higher but uncertain 20 EUR payoff that can be obtained with a probability of $50 \%$ (otherwise nothing), she should compare these two alternatives and select the one that has higher expected value/utility (i.e., $100 \%$ * u(5 EUR) vs. $50 \%$ * u(20 EUR) $+50 \% * \mathrm{u}(0$ EUR $))$. The expected utility model and its alternatives provide a benchmark for normatively superior decisions and are often used for prescriptive reasons. However, their descriptive function (e.g., how good expected utility models are in predicting real behavior) is often debated.

Research has repeatedly demonstrated that the classical expected utility model fails to accurately describe choices (Gilovich, Griffin, \& Kahneman, 2002). People do not follow the assumptions of normative theory. Instead, their behavior under risk and uncertainty tends to be inconsistent, driven by factors irrelevant to the decision problem and restricted by their cognitive limitations as well as the complexity of the task (Simon, 1990). When it comes to the role of numeracy, the main question that arises here is whether more numerate people are more likely to make better financial choices because they adhere to the assumptions of normative theory; alternatively, they rather employ other strategies and processes that may be not always coincide with the normative predictions but enable them to make adaptive choices taking into account the structure of the task and environment. In other words, we address the question of whether superior decisions made by people with high numeracy are preceded by complex cognitive computations (e.g., calculation of EV (expected value)) that lead to a comparison of $\mathrm{EV} /$ utilities or rather result from different operations.

This interesting question was tackled by Cokely and Kelley (2009). In their study, participants completed the test developed by Schwartz et al. (1997) and Lipkus et al. (2001) described above and were presented with 40 choice problems under risk. This paradigmatic task consisted of a series of simple monetary lotteries in which participants had to choose between a certain and risky option each time. To illustrate, in a sample trial a lottery of ‘ $\$ 50$ for certain vs. 50\% chance to gain
$\$ 400^{\prime}$ was displayed to participants and their task was to select the option they preferred. In this example, the $\mathrm{EV}$ of the certain option was $\$ 50$ and the EV of the risky option was $\$ 200$ (i.e., $50 \%$ * \$400); like in this example, a normatively superior option existed in each of the 40 choice problems. Importantly, the process of making a choice was traced by recording retrospective verbal reports after each decision. That is, participants were asked to report the exact thoughts and reasons that they considered when making their choice. Based on this measure, the authors were able to analyze both performance in a risky task and an introspectively-identified cognitive process that preceded it. The results of this study demonstrated that higher numeracy was related to more choices maximizing EV and more frequent verbalization of EV computations. Importantly, it was also related to more frequent verbalization of other considerations such as transforming probabilities (e.g., converting a $66 \%$ probability of success into a $34 \%$ probability of failure; translating percentages into frequencies and vice versa), considering and comparing different gains, losses, and their probabilities. In a mediation analysis the relationship between higher numeracy and more choices maximizing EV was fully explained by what the authors referred to as elaborative heuristic search - "more thorough exploration and representation of the problem space" (Cokely \& Kelley, 2009, p. 22) ${ }^{1}$. That is, people with high numeracy, besides explicit EV computations which require multiplication and addition, considered more aspects of the decision problem, recoded the given probabilities, focused on maximum and minimum differences between outcomes, or took into account their risk preferences. To conclude, this study demonstrated that more numerate people exhibit superior performance not only because they calculate EV but also because they are more likely to engage in elaborative processing of numerical information describing the choice problem.

If people with high numeracy do not simply compute EV but rather base their choices on heuristic processing, maybe they are able to perform such operations faster than people with low numeracy? This problem was investigated in a study by Ghazal et al. (2014). The authors asked participants to make a binary choice on three problems in a financial context (e.g., whether they would prefer 100 EUR for certain or $75 \%$ chance of 200 EUR). Along with choice responses, the authors recorded response latency-i.e., the amount of time from the presentation of the problem to the participant's decision. Two main findings emerged from this study.

1Elaborative heuristic search was operationalized as "the total number of different types of simple considerations verbalized (excluding expected-value calculations and ambiguous codes)" (Cokely \& Kelley, 2009, p. 22) 
First, people with high numeracy were more likely to select the normatively superior options. Second, the relationship between superior performance in the financial task and numeracy was mediated by decision latency. That is, people with high numeracy deliberated more on the decision problems (i.e., spent more time making a choice) which in turn led to more normatively superior decisions. Taken together, the authors concluded that better financial decisions made by more numerate people may result from metacognitive processes that are captured by longer deliberation. That is, more numerate people were also more accurate in evaluating their decisions - they made more accurate judgments on the accuracy on their judgments (Ghazal et al., 2014), however these effects were tested only in the medical domain. In reference to results reported above, longer deliberation likely results from elaborative heuristic processing rather than cognitive processes associated with EV maximization.

The two psychological mechanisms described above (i.e., elaborative heuristic processing and metacognitive processing) may explain a wide range of experimental effects showing superior performance of more numerate people in financial tasks. For example, it has been demonstrated that people with high numeracy are more consistent in their risk preference (Ashby, 2017), more sensitive to variations in EVs (Jasper, Bhattacharya, Levin, Jones, \& Bossard, 2013), and less prone to framing effects and the influence of irrelevant information (Johnson \& Tubau, 2013; Peters \& Levin, 2008). Their pricing of monetary gambles is closer to expected values (Millroth \& Juslin, 2015), which is reflected in more linear utility function (Schley \& Peters, 2014) and less distorted probability weighting (Patalano, Saltiel, Machlin, \& Barth, 2015). Intriguingly, people with high numeracy seem to be flexible in employing choice strategies depending on the task structure and decision environment (Traczyk, Sobkow, et al., 2018). That is, they adaptively select choice strategies and maximize EV when problems are meaningful and lead to substantially higher payoffs. In contrast, in case of trivial choice problems, in which payoffs are similar, they switch to faster and less effortful heuristic strategy.

An interesting line of research also links numeracy and financial decision making to emotions (Peters, 2012). In particular, several studies indicated that more numerate people are able to derive more precise "affective meaning" from numbers-the clarity of affective reaction to numbers in such people is more precisewhich subsequently guides their judgments and choices (Peters et al., 2006). In other words, more numerate people seem to be more sensitive to affect that is directly related to a decision problem and they use this information in the decision-making process.
A greater sensitivity to numbers in more numerate people was also demonstrated in a study that employed a lab-based experimental insurance task (Petrova et al., 2014). Participants were randomly assigned to one of the three conditions. In each condition, they were asked to visualize that they owned a camera, the current market value of which was 500 EUR. Then, they were asked to indicate how much they would pay for insurance against loss or theft of the camera given a probability of loss $(1 \%, 5 \%, 10 \%, 25 \%, 50 \%, 75 \%, 90 \%, 95 \%$, $99 \%$ as a within-subjects factor). In the neutral condition, participants were presented with a common description of the camera (i.e., as it is presented in a web store). In the affective condition, a description of the camera was more affect-rich and highlighted that the camera was a birthday gift from a grandfather. Finally, in the reappraisal condition, the camera was described in the same way as in the affective condition but participants were asked to write down how they would cope with negative consequences of a potential loss or theft. The results showed that people were the most sensitive to changes in probability (of loss/theft of the camera) in the reappraisal condition, while in the affective condition they distorted probabilities to a greater extend. This effect was present among more numerate people. Furthermore, numeracy was also related to higher variance in reported emotions of hope and fear, which predicted higher sensitivity to changes in the probability scale. Accordingly, people with high numeracy experienced more differentiated emotional reactions to probabilities which resulted in higher sensitivity to probabilities and less distorted probability weighting.

Additional studies investigating the relationships between numeracy, affect, and probability weighting indicated that more numerate people are likely to use affect as information depending on its source. For example, Traczyk and Fulawka (2016) used a modified insurance task (described above) to investigate the influence of incidental affect (i.e., affect irrelevant to the decision problem) on probability weighting. Instead of manipulating the affective description of a camera, each insurance decision was preceded by a presentation of unrelated negative or neutral pictures. The results of this study showed that negative affect induced by the pictures influenced sensitivity to changes in probability but only among participants with low numeracy, who were more prone to the impact of incidental and irrelevant affect.

To summarize, several studies demonstrated that the role of numeracy in financial decision making goes beyond calculations. More numerate people seem to deliberate more on decision problems by engaging in elaborative heuristic processing. Interestingly, higher numeracy helps construct an affectively-charged representation of the problem. In this sense, people with 
higher numeracy are able to extract more affective information from numbers that are relevant to their choices and, at the same time, they are less prone to incidental affect that is irrelevant in the decisionmaking process.

\section{The role of numeracy in real-life financial decision making}

Numeracy is a powerful predictor of better decisions not only in paradigmatic risk tasks, but also in real-life financial decisions. Let us think about the following situations: Choosing a credit card, insurance, mortgage, taking a loan, investing in stocks, gambling, etc. Making good decisions in all of these situations requires knowledge about financial concepts (i.e., financial literacy; Fernandes, Lynch, \& Netemeyer, 2014) as well as the ability to understand and perform number-related complex operations (i.e., numeracy). Nevertheless, a substantial number of individuals living across different countries experience serious difficulties in making good financial decisions. Importantly, these difficulties are not limited to complex financial problems only, but are apparent in what must be simple everyday financial decisions.

To illustrate, a recent analysis using data from the Program for International Assessment of Adult Competencies (Bhutoria, Jerrim, \& Vignoles, 2018) conducted by the Organization for Economic Cooperation and Development (OECD) on nationally representative samples of adults in 31counties revealed serious errors that people make in everyday financial decisions. For instance, one out of three respondents from Spain experienced difficulties in calculating a change during usual shopping or in calculating a price of a product given 'per unit' (e.g., per kilo) cost. Moreover, about two thirds of participants misunderstood simple financial graphs. Crucially, average performance across counties in these simple financial tasks predicted national wealth (the per capita Gross Domestic Product, GDP) and explained from 16 to 27 percent of GDP variance. The authors of this report concluded that a substantial number of people (even those living in developed OECD countries) do not have basic skills that are required in real-life financial tasks. They also stress a strong and urgent need for policy intervention to help people become more financially literate.

Financial literacy is usually measured using tasks that require understanding financial concepts (e.g. "Do you think that the following statement is true or false? 'Bonds are normally riskier than stocks.'") or solving financial tasks (e.g., "Suppose you have \$100 in a savings account and the interest rate is $20 \%$ per year and you never withdraw money or interest payments. After 5 years, how much would you have in this account in total?"). These measures predict a wide range of financial behaviors such as having an emergency fund, credit and checking fees, positive savings, etc. (Fernandes et al., 2014). However, these relationships became weaker or even insignificant when controlling for cognitive variables (e.g., numeracy, consumer confidence investing, planning for money, willingness to take investment risks) suggesting the presence of omitted important cognitive variables in many studies on financial literacy. A recent study of Skagerlund, Lind, Strömbäck, Tinghög, and Västfjäll (2018) suggests that numeracy provides the 'computational engine' behind financial operations and as a result can be the central component of this construct. In this study conducted on a representative sample of the general Swedish population, Skagerlund et al. (2018) found that objective numeracy was the strongest predictor of financial literacy, even when controlling for demographics (e.g., age, gender, education, income) and cognitive and emotional factors (e.g., cognitive reflection, self-efficacy, mathematics, and financial anxiety).

The importance of numeracy for real-life financial outcomes was particularly evidenced in a study by EstradaMejia et al., 2016. Based on a large sample of Dutch adults, they found a significant correlation between numeracy and personal wealth. Wealth was calculated on the basis of declared assets and liabilities (e.g., saving accounts, stocks, bonds, real estate, mortgages, loans, credits). Authors estimated that on average a one-point increase in numeracy (Lipkus et al., 2001) was associated with 5 percent more personal wealth. The effect of numeracy was similar in magnitude to the effects of income or having a university degree. Moreover, the relationship between numeracy and wealth was significant even when other measures (e.g., differences in education, risk preferences, financial knowledge, seeking financial advice, beliefs about future income or need for cognition) were factored out, indicating that numeracy is a robust and independent predictor of personal wealth. Moreover, numeracy was found to be a key determinant of wealth accumulation over time. During a 5-year period people with low numeracy tended to decumulate wealth while those with high numeracy had a similar level of wealth.

Altogether, results of the abovementioned studies indicate that numerical abilities are crucial not only for individuals (those with higher numeracy tend to be more financially literate and accumulate more personal wealth over time), but also for society and economics (numerical abilities in the population are associated with national wealth).

\section{Interventions: How to improve numeracy and informed decision making?}

Despite a bulk of empirical research showing the predictive power of numeracy in the medical and financial 
domains, evidence on the effectiveness of trainings or education programs aimed at improving numeracy and informed decision making is scarce.

The widely shared intuition is that financial education programs could effectively improve real-life financial decision making. However, a meta-analysis conducted by Fernandes et al. (2014) revealed that this effect is minor and vanishes after few months. Moreover, people with low income, who should be the main target of these programs, benefit the least. These disappointing results indicate the need for complementary or alternative psychological methods that could help improve decision making, especially in people with low numeracy and/or low income.

Currently, we can observe a growing market of 'brain-training' companies offering cognitive trainings that one could perform using a personal computer or a smart phone. This trend aimed at improving brain and cognitive functioning seems to be very promising. However, a recent review by Simons et al. (2016) stressed the need for developing standards in designing these interventions and conducting research validating their effectiveness (such as introducing experimental designs with an appropriate active control condition). Moreover, Simons et al. (2016) suggested that braintraining interventions improve performance in trained tasks, but there is little evidence for transfer effectsi.e., improvement in other cognitive tasks or daily life measures. For example, a recent study by Kable et al. (2017) revealed that one of the most popular commercial training programs (ten weeks of games designed to enhance executive functions such as working memory, problem solving, or speed) was ineffective at improving performance and altering neural activity in decision tasks regarding delay discounting or risky choices (i.e., financial lotteries).

Having in mind the results reviewed so far, we argue that interventions aiming to improve numeracy hold promise for improving decision making across diverse contexts. One of the first studies testing this proposition was conducted by Peters and colleagues (Peters et al., 2017). In a longitudinal experiment, students enrolled in a statistics course were randomly assigned to one of two experimental conditions: Value affirmation manipulation vs. control. In the experimental condition, participants ranked six values (religion, knowledge, relationships, etc.) by personal importance and indicated why their most important value is important and meaningful to them. This manipulation was intended to change perception of statistics classes and to make students benefit more from this course. Results showed that subjective numeracy (i.e., a self-reported measure of how people perceive their numerical ability) declined over time in the control condition, whereas in the experimental condition it remained stable. In addition, the combination of statistical education and value affirmation improved objective numeracy (i.e., a math testbased measure of how people perform with numbers and number operations). Interestingly, the authors also observed a significant indirect-only effect of the intervention via subjective and objective numeracy on financial outcomes, financial literacy and health behaviors what suggests possible transfer of increased numeracy to real-life outcomes.

Besides value affirmation, an alternative approach to improve numeracy could aim at a more basic and evolutionarily old mechanism related to the approximate number system. The ability to exactly perceive and manipulate numerosities as well as map symbolic numbers to magnitudes seems to be the precursor of objective numerical skills (Peters \& Bjalkebring, 2015). Previous research demonstrated that trainings of the approximate number system (Park \& Brannon, 2013) or mental number line (Kucian et al., 2011) transfers into performance on symbolic arithmetic tasks. However, up to date there is no scientific evidence for such types of training on numeracy and/or decision-making, so this approach yet promising demands further investigation.

In summary, scientific research has not provided the golden standard or a well-documented evidence-based intervention improving numeracy and decision making. However, previous research shows that this approach is promising. One of the greatest challenges facing researchers and policy makers would be to develop, test, and implement such interventions or programs that could be helpful for many vulnerable individuals and society in general. Another option would be the use of powerful, simple interventions such as visual aids and analogies that can have substantial benefits at minimal costs, particularly when designed to serve vulnerable populations with limited numeracy (Galesic \& GarcíaRetamero, 2013; García-Retamero \& Cokely, 2013, 2017). These interventions robustly improve risk understanding in diverse individuals by encouraging thorough deliberation, enhancing cognitive self-assessment, and reducing conceptual biases in memory.

Finally, in this review we have focused on the benefits of high vs. low numeracy for decision making. However, whereas high numeracy can certainly help improve understanding and decision making, it will not be a panacea for all problems. For instance, information that is presented in a non-transparent way can mislead and confuse even those with high numeracy (GarcíaRetamero \& Cokely, 2017). In addition, there are problems that are notoriously difficult to solve even when presented transparently. One example is problems that require Bayesian inference such as deducing the probability of having a medical condition given a positive screening test. Although people with high numeracy are generally better at solving these problems, high 
numeracy alone is likely to be insufficient to promote optimal choices under all conditions (see e.g., Chapman \& Liu, 2009; Johnson \& Tubau, 2013). This suggests that interventions and training directed at improving specific types of decisions are likely to be more successful if they also consider the context and the structure of decision problems, besides the numerical abilities of the recipients.

A large body of research from all over the world has demonstrated that low numeracy is important for a variety of health and financial outcomes. Studies with diverse samples show that low numeracy is prevalent in general population samples and found even in samples of highly qualified professionals (García-Retamero, Cokely, Wicki, \& Joeris, 2016). In this review, we have illustrated that compared to people with low numeracy, people with high numeracy are at lower risk of negative outcomes such as disease or financial loss. Importantly, research points that the main reason for this advantage is superior decision making. Decision strategies reflected in the exploration of the decision space, processing of numerical information, and weighing and "feeling" decision options are some of the mechanisms that can explain the effects of numeracy on decisions and outcomes. These emerging research lines show that numeracy goes beyond calculations and computations of proportions (Peters, 2012) and that numeracy tests successfully capture the skills necessary for effective naturalistic decision making (e.g., more successfully than traditionally used fluid intelligence tests, see Cokely et al., 2018). Despite the overwhelming evidence on the importance of numeracy, interventions aiming to improve statistical numeracy and thus produce lasting and transferable improvements in decision making are still scarce and further research on mechanisms is needed to inform the design of such interventions. We also believe that the time has come to attempt a quantitative synthesis (i.e., meta-analysis) on the effects of numeracy on different aspects of decision making such as perceptions or choice. These ventures can bring us closer to reducing the gap between more and less numerate people, giving the latter ones an equal opportunity to be autonomous and informed citizens of the modern world.

\section{References}

Ancker J. S., \& Kaufman D. (2007). Rethinking health numeracy: A multidisciplinary literature review. Journal of the American Medical Informatics Association, 14, 713-721. https://doi.org/10.1197/jamia.M2464

Anderson B. L., \& Schulkin J. (2014). Physicians' understanding and use of numeric information. In B. L. Anderson, \& J. Schulkin (Eds.), Numerical reasoning in judgments and decision making about health (pp. 59-79). Cambridge, UK: Cambridge University Press.
Apter A. J., Cheng J., Small D., Bennett I. M., Albert C., Fein D. G., ... \& van Horne S. (2006). Asthma numeracy skill and health literacy. Journal of Asthma, 43(9), 705-710. https: / / doi.org/10.1080/02770900600925585

Apter A. J., Wang X., Bogen D., Bennett I. M., Jennings R. M., García L., ... Have T. T. (2009). Linking numeracy and asthma-related quality of life. Patient Education and Counseling, 75, 386-391. https://doi.org/10.1016/ j.pec.2009.01.003

Ashby N. J. S. (2017). Numeracy predicts preference consistency : Deliberative search heuristics increase choice consistency for choices from description and experience. Judgement and Decision Making, 12(2), 128-139.

Baron J. (2008). Thinking and deciding ( $4^{\text {th }}$ Ed.). Cambridge, UK: Cambridge University Press.

Bhutoria A., Jerrim J., \& Vignoles A. (2018). The financial skills of adults across the world. New estimates from PIAAC. (Working Paper). Retrieved from https://johnjerrim. files.wordpress.com/2018/03/piaac_working_report_ march_2018.docx

Broniatowski D. A., \& Reyna V. F. (2017). A formal model of fuzzy-trace theory: Variations on framing effects and the Allais Paradox. Decision, 5(4), 205-252. https://doi. org/10.1037/dec0000083

Chapman G. B., \& Liu J. (2009). Numeracy, frequency, and Bayesian reasoning. Judgment and Decision Making, 4(1), 34-40.

Cokely E. T., Galesic M., Schulz E., Ghazal S., \& García-Retamero R. (2012). Measuring risk literacy: The Berlin Numeracy Test. Judgment and Decision Making, 7, 25-47.

Cokely E. T., Ghazal S., Galesic M., García-Retamero R., \& Schulz E. (2012). How to measure risk comprehension in educated samples. In R. Garcia-Retamero \& M. Galesic (Eds.), Transparent communication of health risks (pp. 29-52). New York, NY: Springer.

Cokely E. T., Ghazal S., \& García-Retamero R. (2014). Measuring numeracy. In B. L. Anderson \& J. Schulkin (Eds.), Numerical reasoning in judgments and decision making about health (pp. 11-38). Cambridge, UK: Cambridge University Press.

Cokely E. T., Feltz A., Ghazal S., Allan J. N., Petrova D., \& García-Retamero R. (2018). Decision making skill: From intelligence to numeracy and expertise. In K. A. Ericsson, R. R. Hoffman, A. Kozbelt, \& A. M. Williams (Eds.), Cambridge handbook of expertise and expert performance ( $2^{\text {nd }}$ Ed., pp. 476-505). New York, NY: Cambridge University Press.

Cokely E. T., \& Kelley C. M. (2009). Cognitive abilities and superior decision making under risk : A protocol analysis and process model evaluation. Judgement and Decision Making, 4(1), 20-33.

Davids S. L., Schapira M. M., McAuliffe T. L., \& Nattinger A. B. (2004). Predictors of pessimistic breast cancer risk perceptions in a primary care population. Journal of General Internal Medicine, 19(4), 310-315. https://doi.org/10.1111/j.1525-1497.2004.20801.x

Estrada C. A., Martin-Hryniewicz M., Collins C., Byrd J. C., \& Peek B. T. (2004). Literacy and numeracy skills and anticoagulation control. The American Journal of the Medical 
Sciences, 328(2), 88-93. https:/ / doi.org/10.1097/00000441200408000-00004

Estrada-Mejía C., de Vries M., \& Zeelenberg M. (2016). Numeracy and wealth. Journal of Economic Psychology, 54, 53-63. https:/ / doi.org/10.1016/j.joep.2016.02.011

Fagerlin A., Ubel P. A., Smith D. M., \& Zikmund-Fisher B. J. (2007). Making numbers matter: Present and future research in risk communication. American Journal of Health Behavior, 31(Suppl. 1), S47-S56. https:/ / doi.org/10.5555/ ajhb.2007.31.supp.S47

Fernandes D., Lynch J. G., Jr., \& Netemeyer R. G. (2014). Financial literacy, financial education, and downstream financial behaviors. Management Science, 60(8), 1861-1883. https: / / doi.org/10.1287/mnsc.2013.1849

Gaissmaier W., Giese H., Galesic M., García-Retamero R., Kasper J., Kleiter I., ... \& Heesen C. (2018). Numeracy of multiple sclerosis patients: A comparison of patients from the PERCEPT study to a German probabilistic sample. Patient Education and Counseling, 101, 74-78, https:/ / doi. org/10.1016/j.pec.2017.07.018

Galesic M., \& García-Retamero R. (2010). Statistical numeracy for health: A cross-cultural comparison with probabilistic national samples. Archives of Internal Medicine, 170, 462-468. https://doi.org/10.1001/ archinternmed.2009.481

Galesic M., \& García-Retamero R. (2011). Do low-numeracy people avoid shared decision making? Health Psychology, 30, 336-341. https://doi.org/10.1037/a0022723

Galesic M., \& García-Retamero R. (2013). Using analogies to communicate information about health risks. Applied Cognitive Psychology, 27, 33-42. https://doi.org/10.1002/ acp. 2866

García-Retamero R., Andrade A., Sharit J., \& Ruiz J. G. (2015). Is patients' numeracy related to physical and mental health? Medical Decision Making, 35(4), 501-511. https:/ / doi.org/10.1177/0272989X15578126

García-Retamero R., \& Cokely E. T. (2013). Communicating health risks with visual aids. Current Directions in Psychological Science, 22, 392-399. https: / / doi.org/10.1177/0963721413491570

García-Retamero R., \& Cokely E. (2014). The influence of skills, message frame, and visual aids on prevention of sexually transmitted diseases. Journal of Behavioral Decision Making, 27, 179-189. https://doi.org/10.1002/ bdm.1797

García-Retamero R., \& Cokely E. T. (2017). Designing visual aids that promote risk literacy: A systematic review of health research and evidence-based design heuristics. Human Factors, 59, 582-627. https: / / doi. org/10.1177/0018720817690634

García-Retamero R., Cokely E. T., \& Hoffrage U. (2015). Visual aids improve diagnostic inferences and metacognitive judgment calibration. Frontiers in Psychology, 6, article 932. https://doi.org/10.3389/fpsyg.2015.00932

García-Retamero R., Cokely E. T., Wicki B., \& Joeris A. (2016). Improving risk literacy in surgeons. Patient Education and Counseling, 99, 1156-1161. https://doi. org/10.1016/j.pec.2016.01.013

García-Retamero R., \& Galesic M. (2009). Communicating treatment risk reduction to people with low numeracy skills: A cross-cultural comparison. American Journal of Public Health, 99(12), 2196-2202. https:/ /doi.org/10.2105/ AJPH.2009.160234

García-Retamero R., \& Galesic M. (2010). How to reduce the effect of framing on messages about health. Journal of General Internal Medicine, 25, 1323-1329. https:/ / doi. org/10.1007/s11606-010-1484-9

García-Retamero R., \& Galesic M. (2011). Using plausible group sizes to communicate information about medical risks. Patient Education and Counseling, 84, 245-250. https://doi.org/10.1016/j.pec.2010.07.027

García-Retamero R., \& Galesic M. (2013). Transparent communication of health risks: Overcoming cultural differences. New York, NY: Springer.

García-Retamero R., \& Hoffrage U. (2013). Visual representation of statistical information improves diagnostic inferences in doctors and their patients. Social Science E Medicine, 83, 27-33. https: / / doi. org/10.1016/j.socscimed.2013.01.034

García-Retamero R., Wicki B., Cokely E. T., \& Hanson B. (2014). Factors predicting surgeons' preferred and actual roles in interactions with their patients. Health Psychology, 33, 920-928. https://doi.org/10.1037/hea0000061

Gardner P. H., McMillan B., Raynor D. K., Woolf E., \& Knapp P. (2011). The effect of numeracy on the comprehension of information about medicines in users of a patient information website. Patient Education and Counseling, 83(3), 398-403. https: / / doi.org/10.1016/ j.pec.2011.05.006

Ghazal S., Cokely E. T., \& García-Retamero R. (2014). Predicting biases in very highly educated samples: Numeracy and metacognition. Judgment and Decision Making, 9(1), 15-34.

Gigerenzer G., Gaissmaier W., Kurz-Milcke E., Schwartz L. M., \& Woloshin S. (2007). Helping doctors and patients make sense of health statistics. Psychological Science in the Public Interest, 8(2), 53-96. https:/ / doi. org/10.1111/j.1539-6053.2008.00033.x

Gilovich T., Griffin D., \& Kahneman D. (Eds.) (2002). Heuristics and biases: The psychology of intuitive judgment. Cambridge, UK: Cambridge University Press.

Ginde A. A., Clark S., Goldstein J. N., \& Camargo C. A., Jr., (2008). Demographic disparities in numeracy among emergency department patients: Evidence from two multicenter studies. Patient Education and Counseling, 72(2), 350-356. https://doi.org/10.1016/ j.pec.2008.03.012

Gurmankin A. D., Baron J., \& Armstrong K. (2004). Intended message versus message received in hypothetical physician risk communications: Exploring the gap. Risk Analysis, 24, 1337-1347. https://doi. org/10.1111/j.0272-4332.2004.00530.x

Huizinga M. M., Beech B. M., Cavanaugh K. L., Elasy T. A., \& Rothman R. L. (2008). Low numeracy skills are associated with higher BMI. Obesity, 16(8), 1966-1968. https:/ / doi. org/10.1038/oby.2008.294

Jasper J. D., Bhattacharya C., Levin I. P., Jones L., \& Bossard E. (2013). Numeracy as a predictor of adaptive risky decision making. Journal of Behavioral Decision Making, 26(2), 164-173. https://doi.org/10.1002/bdm.1748 
Johnson E. D., \& Tubau E. (2013). Words, numbers, \& numeracy: Diminishing individual differences in Bayesian reasoning. Learning and Individual Differences, 28, 34-40. https:/ / doi.org/10.1016/j.lindif.2013.09.004

Johnson E. D., \& Tubau E. (2017). Structural mapping in statistical word problems: A relational reasoning approach to Bayesian inference. Psychonomic Bulletin $\mathcal{E}$ Review, 24(3), 964-971. https://doi.org/10.3758/s13423-016-1159-6

Kable J. W., Caulfield M. K., Falcone M., McConnell M., Bernardo L., Parthasarathi T., ... Lerman C. (2017). No effect of commercial cognitive training on neural activity during decision-making. The Journal of Neuroscience, 37, 7390-7402. https://doi.org/10.1523/JNEUROSCI.2832-16.2017

Kaplan R. M., \& Frosch D. L. (2005). Decision making in medicine and health care. Annual Review of Clinical Psychology, 1, 525-556. https://doi.org/10.1146/ annurev.clinpsy.1.102803.144118

Kucian K., Grond U., Rotzer S., Henzi B., Schönmann C., Plangger F., ... von Aster M. (2011). Mental number line training in children with developmental dyscalculia. NeuroImage, 57(3), 782-795. https://doi.org/10.1016/ j.neuroimage.2011.01.070

Kutner M., Greenburg E., Jin Y., \& Paulsen C. (2006). The Health Literacy of America's Adults: Results from the 2003 National Assessment of Adult Literacy. NCES 2006-483. Washington, WA: National Center for Education Statistics.

Lipkus I. M., Samsa G., \& Rimer B. K. (2001). General performance on a numeracy scale among highly educated samples. Medical Decision Making, 21(1), 37-44. https: / / doi.org/10.1177/0272989X0102100105

Manganello J. A., \& Clayman M. L. (2011). The association of understanding of medical statistics with health information seeking and health provider interaction in a national sample of young adults. Journal of Health Communication, 16(Suppl. 3), 163-176. https:/ / doi.org/10.1080/10810730.2011.604704

McCaffery K. J., Smith S. K., \& Wolf M. (2010). The challenge of shared decision making among patients with lower literacy: A framework for research and development. Medical Decision Making, 30(1), 35-44. https:/ / doi. org/10.1177/0272989X09342279

McNair S., \& Feeney A. (2015). Whose statistical reasoning is facilitated by a causal structure intervention? Psychonomic Bulletin \& Review, 22(1), 258-264. https: / / doi.org/10.3758/ s13423-014-0645-y

Millroth P., \& Juslin P. (2015). Prospect evaluation as a function of numeracy and probability denominator. Cognition, 138, 1-9. https://doi.org/10.1016/j.cognition.2015.01.014

Paasche-Orlow M. K., \& Wolf M. S. (2007). The causal pathways linking health literacy to health outcomes. American Journal of Health Behavior, 31(1), S19-S26.

Pachur T., \& Galesic M. (2013). Strategy selection in risky choice: The impact of numeracy, affect, and cross-cultural differences. Journal of Behavioral Decision Making, 26(3), 260-271. https://doi.org/10.1002/bdm.1757

Park J., \& Brannon E. M. (2013). Training the approximate number system improves math proficiency. Psychological Science, 24(10), 2013-2019. https:/ / doi. org/10.1177/0956797613482944

Patalano A. L., Saltiel J. R., Machlin L., \& Barth H. (2015). The role of numeracy and approximate number system acuity in predicting value and probability distortion. Psychonomic Bulletin \& Review, 22(6), 1820-1829. https:/ / doi.org/10.3758/s13423-015-0849-9

Peters E. (2012). Beyond comprehension: The role of numeracy in judgments and decisions. Current Directions in Psychological Science, 21(1), 31-35. https://doi. org/10.1177/0963721411429960

Peters E., \& Bjalkebring P. (2015). Multiple numeric competencies: When a number is not just a number. Journal of Personality and Social Psychology, 108(5), 802-822. https://doi.org/10.1037/pspp0000019

Peters E., \& Levin I. P. (2008). Dissecting the risky-choice framing effect : Numeracy as an individual-difference factor in weighting risky and riskless options. Literacy, 3(6), 435-448.

Peters E., Shoots-Reinhard B., Tompkins M. K., Schley D., Meilleur L., Sinayev A., ... Crocker J. (2017). Improving numeracy through values affirmation enhances decision and STEM outcomes. PloS ONE, 12(7), e0180674. https:/ / doi.org/10.1371/journal.pone.0180674

Peters E., Västfjäll D., Slovic P., Mertz C. K., Mazzocco K., \& Dickert S. (2006). Numeracy and decision making. Psychological Science, 17(5), 407-413. https:/ / doi. org/10.1111/j.1467-9280.2006.01720.x

Petrova D., García-Retamero R., Catena A., \& van der Pligt J. (2016). To screen or not to screen: What factors influence complex screening decisions? Journal of Experimental Psychology: Applied, 22(2), 247. https: / / doi.org/10.1037/ xap0000086

Petrova D., García-Retamero R., Catena A., Cokely E. T., Heredia Carrasco A., Arrebola Moreno A., \& RamírezHernández J. A. (2017). Numeracy predicts risk of pre-hospital decision delay: A retrospective study of acute coronary syndrome survival. Annals of Behavioral Medicine, 51, 292-306. https://doi.org/10.1007/s12160-016-9853-1

Petrova D., Kostopoulou O., Delaney B. C., Cokely E. T., \& García-Retamero R. (2017). Strengths and gaps in physicians' risk communication: A scenario study of the influence of numeracy on cancer screening communication. Medical Decision Making, 38(3), 355-365. https: / / doi. org/10.1177/0272989X17729359

Petrova D. G., van der Pligt J., \& García-Retamero R. (2014). Feeling the numbers: On the interplay between risk, affect, and numeracy. Journal of Behavioral Decision Making, 27(3), 191-199. https:/ / doi.org/10.1002/bdm.1803

Portnoy D. B., Roter D., \& Erby L. H. (2010). The role of numeracy on client knowledge in BRCA genetic counseling. Patient Education and Counseling, 81(1), 131-136. https:/ / doi.org/10.1016/j.pec.2009.09.036

Reyna V. F., Nelson W. L., Han P. K., \& Dieckmann N. F. (2009). How numeracy influences risk comprehension and medical decision making. Psychological Bulletin, 135, 943-973. https:/ / doi.org/10.1037/a0017327

Rodríguez V., Andrade A. D., García-Retamero R., Anam R., Rodríguez R., Lisigurski M., ... Ruiz J. G. (2013). Health literacy, numeracy, and graphical literacy among veterans in primary care and their effect on shared decision-making and trust in physicians. Journal of Health Communication, 18, 273-289. https: / / doi.org/10.1080/10810730.2013.829137 
Rothman R. L., Housam R., Weiss H., Davis D., Gregory R., Gebretsadik T., ... \& Elasy T. A. (2006). Patient understanding of food labels: The role of literacy and numeracy. American Journal of Preventive Medicine, 31, 391-398. https://doi.org/10.1016/j. amepre.2006.07.025

Roter D. L. (2005). Health literacy and the patient-provider relationship. In J. G. Schwartzberg, J van Geest, \& C. C. Wang (Eds.), Understanding health literacy: Implications for medicine and public health (pp. 87-100). Chicago, IL: AMA Press.

Sharit J., Lisigurski M., Andrade A. D., Karanam C., Nazi K. M., Lewis J. R., \& Ruiz J. G. (2014). The roles of health literacy, numeracy, and graph literacy on the usability of the VA's personal health record by veterans. Journal of Usability Studies, 9, 173-193.

Schley D. R., \& Peters E. (2014). Assessing "economic value": Symbolic-number mappings predict risky and riskless valuations. Psychological Science, 25(3), 753-761. https:/ / doi.org/10.1177/0956797613515485

Schwartz L. M., Woloshin S., Black W. C., \& Welch H. G. (1997). The role of numeracy in understanding the benefit of screening mammography. Annals of Internal Medicine, 127(11), 966-972. https:/ / doi.org/10.7326/0003-4819-12711-199712010-00003

Simon H. A. (1990). Invariants of human behavior. Annual Review of Psychology, 41(1), 1-20. https:/ /doi.org/10.1146/ annurev.ps.41.020190.000245

Simons D. J., Boot W. R., Charness N., Gathercole S. E., Chabris C. F., Hambrick D. Z., \& Stine-Morrow E. A. L. (2016). Do "brain-training" programs work? Psychological Science in the Public Interest, 17(3), 103-186. https:/ / doi. org $/ 10.1177 / 1529100616661983$

Skagerlund K., Lind T., Strömbäck C., Tinghög G., \& Västfjäll D. (2018). Financial literacy and the role of numeracy - How individuals' attitude and affinity with numbers influence financial literacy. Journal of Behavioral and Experimental Economics, 74, 18-25. https://doi. org/10.1016/j.socec.2018.03.004

Starmer C. (2000). Developments in non-expected utility theory: The hunt for a descriptive theory of choice under risk. Journal of Economic Literature, 38(2), 332-382. https:/ / doi.org/10.1257/jel.38.2.332

Traczyk J., \& Fulawka K. (2016). Numeracy moderates the influence of task-irrelevant affect on probability weighting. Cognition, 151, 37-41. https: / / doi.org/10.1016/j. cognition.2016.03.002

Traczyk J., Lenda D., Serek J., Fulawka K., Tomczak P., Strizyk K., ... Sobkow A. (2018). Does fear increase search effort in more numerate people? An experimental study investigating information acquisition in a decision from experience task. Frontiers in Psychology, 9, article 1203. https:/ / doi.org/10.3389/fpsyg.2018.01203

Traczyk J., Sobkow A., Fulawka K., Kus J., Petrova D., \& García-Retamero R. (2018). Numerate decision makers don't use more effortful strategies unless it pays: A process tracing investigation of skilled and adaptive strategy selection in risky decision making. Judgment and Decision Making, 13(4), 372-381.

von Neumann J., \& Morgenstern O. (1944). Theory of games and economic behavior. Princeton, NJ: Princeton University Press.

von Wagner C., Steptoe A., Wolf M. S., \& Wardle J. (2009). Health literacy and health actions: A review and a framework from health psychology. Health Education \& Behavior, 36(5), 860-877. https: / / doi. org /10.1177/1090198108322819

Waldrop-Valverde D., Jones D. L., Gould F., Kumar M., \& Ownby R. L. (2010). Neurocognition, health-related reading literacy, and numeracy in medication management for HIV infection. AIDS Patient Care and STDs, 24(8), 477-484. https:/ / doi.org/10.1089/apc.2009.0300

Weinfurt K. P., Castel L. D., Li Y., Sulmasy D. P., Balshem A. M., Benson A. B., III., ... Meropol N. J. (2003). The correlation between patient characteristics and expectations of benefit from Phase I clinical trials. Cancer, 98, 166-175. https://doi.org/10.1002/cncr.11483

Zikmund-Fisher B. J., Mayman G., \& Fagerlin A. (2014). Patient numeracy: What do patients need to recognize, think or do with health numbers. In B. L. Anderson \& J. Schulkin (Eds.), Numerical reasoning in judgments and decision making about health (pp. 80-104.). Cambridge, UK: University Press. 